\title{
Discriminatory indices of response of patients with rheumatoid arthritis treated with D-penicillamine
}

\author{
J. S. DIXON, M. E. PICKUP, J. R. LOWE, C. HALLETT, \\ M. R. LEE, AND V. WRIGHT \\ From the Clinical Pharmacology Unit, Royal Bath Hospital, Harrogate, North Yorkshire, and the University \\ Department of Medicine, the General Infirmary at Leeds
}

\begin{abstract}
SUMMARY A long-term study is being undertaken to classify drugs used as specific agents in the treatment of rheumatoid arthritis in terms of their effects on biochemical and clinical characteristics of the disease. In particular it is hoped to establish those indices which are most relevant to the response of RA to treatment. Fifteen patients were treated with D-penicillamine after an initial period of 2 weeks on aspirin alone, when the baseline investigations were made. The dose of penicillamine was increased gradually to a maximum of $500 \mathrm{mg}$ a day over the period of 6 months, and changes in 8 clinical and 25 laboratory indices were measured on 8 separate occasions in the 6-month period. Marked clinical improvement took place, and this was mirrored by changes in a wide range of biochemical parameters. ESR and C-reactive protein were shown to be the most suitable indices of disease improvement with penicillamine treatment.
\end{abstract}

A useful additional tool in the evaluation of rheumatoid arthritis (RA) over recent years has been the simultaneous estimation of a number of blood components known to change in active disease and which provide an objective measure of disease activity. This work has been reviewed by Haataja ${ }^{1}$ and Kendall. ${ }^{2}$

In addition it has been shown that improvement in the disease (i.e., a change in the course of the disease rather than symptomatic relief) is accompanied by a return towards normality in some of these systemic measurements such as the acute phase proteins, ESR, ${ }^{34}$ and serum sulphydryl levels. ${ }^{5}$

The present detailed study was designed to confirm the reported abnormalities in systemic measurements, to investigate whether changes in other systemic variables followed the course of the disease, and to establish the laboratory measurements which best correlate with clinical indices of disease activity during treatment with D-penicillamine. These measurements may well provide information not only as to the best laboratory test to apply as an objective measure of disease activity but also give

Accepted for publication 24 July 1979

Correspondence to Dr M. E. Pickup, Clinical Pharmacology Unit, Royal Bath Hospital, Cornwall Road, Harrogate HG1 2PS. insight into the pathogenesis of the disease and possible mechanisms of drug action.

\section{Patients and methods}

PATIENTS

Fifteen patients ( 12 female, mean age $52 \cdot 6$, range 36-66 years; 3 male, mean age $43 \cdot 3$, range $38-51$ years) were included in the study. All had classical or definite RA (ARA criteria). In addition patients showed evidence of at least moderate disease activity as judged by the presence of at least 3 of the following 5 criteria: (a) tenderness of more than 6 joints; (b) swelling of more than 3 joints; (c) morning stiffness longer than 45 minutes; $(d)$ articular index more than 20 ; (e) ESR more than $28 \mathrm{~mm} \cdot \mathrm{h}^{-1}$.

None of the patients had received specific antirheumatoid drug therapy (e.g., gold, penicillamine, hydroxychloroquine) before the present study. Two patients were on prednisolone $1.5 \mathrm{mg}$ daily and $7 \mathrm{mg}$ daily respectively. Each patient agreed to participate after a full explanation had been given.

\section{DRUG DOSAGE}

D-penicillamine $125 \mathrm{mg} /$ day $(0 \rightarrow 2$ weeks $), 250 \mathrm{mg} /$ day $(2 \rightarrow 4$ weeks), $375 \mathrm{mg} /$ day $(4 \rightarrow 8$ weeks), 500 $\mathrm{mg} /$ day $(8 \rightarrow 24$ weeks). An initial 2-week period during which patients were asked to take $3.9 \mathrm{G}$ 
Nuseal aspirin per day established baseline conditions for clinical and systemic parameters. Nuseal aspirin was also prescribed as required as supplementary treatment during the 6-month dosage period. No other drugs were allowed.

\section{ASSESSMENT PROCEDURES}

Patients were assessed in terms of clinical, biochemical, and immunological status at weeks $0,2,4$, $8,12,16,20$, and $24(0=$ date of starting penicillamine therapy).

\section{CLINICAL MEASUREMENTS}

Clinical assessments, made without reference to previous assessments, were:

\section{A. Subjective}

(i) Pain score-recorded each night on a 1 to 5 scale representing nil, mild, moderate, severe and unbearable pain respectively. A mean figure was obtained from data recorded during the week prior to assessment.

(ii) Change score-visual analogue scale. Patients were asked to score on a line $20 \mathrm{~cm}$ long their feelings (best possible-worst possible) compared with those at the last assessment (taken as the central point on the line). A new line was used for each assessment. A summated change score was obtained at each assessment by addition or subtraction of the individual change scores recorded up to that time.

(iii) Early morning stiffness in minutes.

\section{B. Objective}

(i) Articular index. ${ }^{6}$

(ii) Grip strength-measured with a sphygmomanometer cuff inflated to $30 \mathrm{mmHg}$. The mean of 3 readings on each hand was recorded and the 2 figures averaged.

(iii) Joint circumference-measured with a Geigy arthrocircometer and a mean on the 10 digits recorded.

(iv) Functional grade-recorded on a 1 to 5 scale representing completely mobile, mobile with some difficulty, mobile with a stick, confined to the house, and bedfast respectively.

(v) Aspirin usage-the number of tablets taken daily (each-325 $\mathrm{mg}$ aspirin) was noted by each patient and the mean daily intake over the week prior to each assessment recorded.

\section{SYSTEMIC MEASUREMENTS}

These were measured without knowledge of the clinical status of the patient. They include routine liver function, renal function, haematological and immunological tests, as well as specific tests of particular relevance to rheumatoid disease. Sali- cylate plasma levels were measured, primarily as a check on the patients' quoted daily intake of aspirin. Brief analytical details of those parameters measured in addition to routine procedures are given in Table 1.

\section{STATISTICAL METHODS}

Week 0 values of each systemic parameter were compared with those of normal subjects matched for age and sex, using the Wilcoxon matched pairs signed rank test. ${ }^{7}$

Week 0 values were also compared with each of the 7 time points using the multiple range extension to Friedman's two-way rank test. ${ }^{8}$ Pearson correlation coefficients $(r)$ were calculated using all individual data points. ${ }^{9}$ In addition a multiple correlation ( $R$ ) was calculated between the set of clinical values and each systemic parameter in turn. ${ }^{10}$ All $\mathbf{P}$ values given are 2-tailed.

\section{Results}

Of the 15 patients entered 1 withdrew after 4 weeks owing to development of a rash, and 2 failed to respond to therapy measured in both clinical and systemic terms.

Mean data $( \pm \mathrm{SE})$ for clinical and systemic variables are presented in Figs. 1 and 2 respectively. Table 2 shows the mean laboratory data for normal volunteers, matched for age and sex and measured by identical procedures to those described for patients. Also shown is the normal range for each variable taken from the literature and an indication of whether week 0 values are increased or decreased compared with the matched controls.

Most clinical and laboratory parameters showing some degree of abnormality at week 0 returned towards normality by weeks 12-16 of drug therapy. This was observed in terms of mean data (Figs. 1 and 2) and in individual responders (Fig. 3a). Less marked changes however were recorded in those patients who responded poorly. For example, articular index and serum sulphydryl changes in a poor responder (Fig. 3b) can be compared with

Table 1 Analytical details-biochemical variables

\begin{tabular}{ll}
\hline Parameter & Method and reference \\
\hline Fibrinogen & Immunodiffusion 43 \\
Haptoglobin & Column chromatography44 \\
C-reactive protein (CRP) & Immunodiffusion ${ }^{43}$ \\
Plasma gamma glutamyl & \\
transpeptidase & Colourimetric45 \\
Plasma viscosity & Ostwald viscometry46 \\
Serum total sulphydryl & Spectrophotometric ${ }^{31}$ \\
Serum histidine & Spectrofluorometric77 \\
Plasma salicylate & Spectrophotometric48 \\
\hline
\end{tabular}



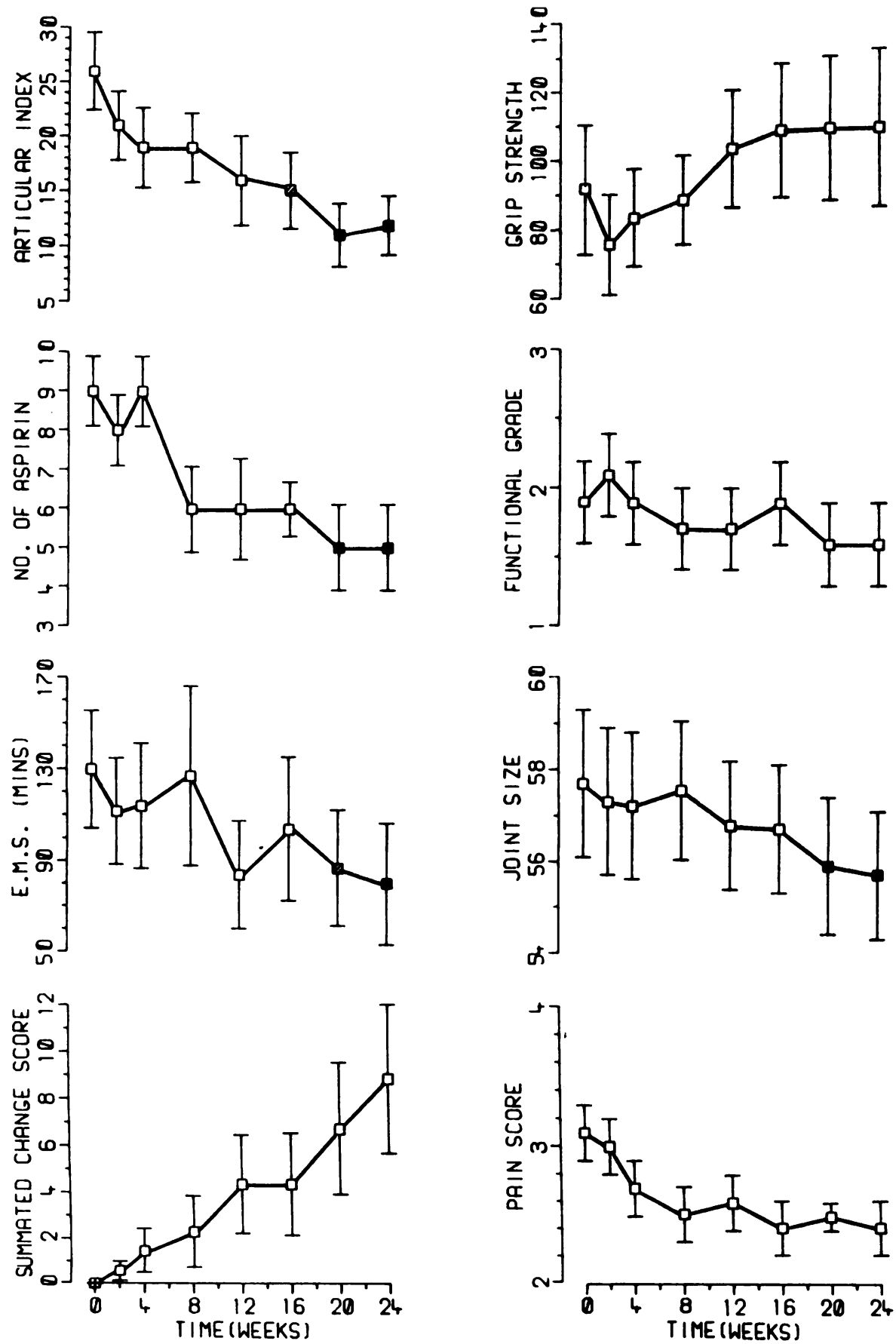

Fig. 1 Clinical data (mean $\pm S E$ ) for 15 RA patients treated for 6 months with D-penicillamine. Changes in individual parameters reaching statistical significance (Friedman rank test) when compared with data at week 0 are indicated by hatched $(P<0.05)$ and closed $(P<0.01)$ data points. 

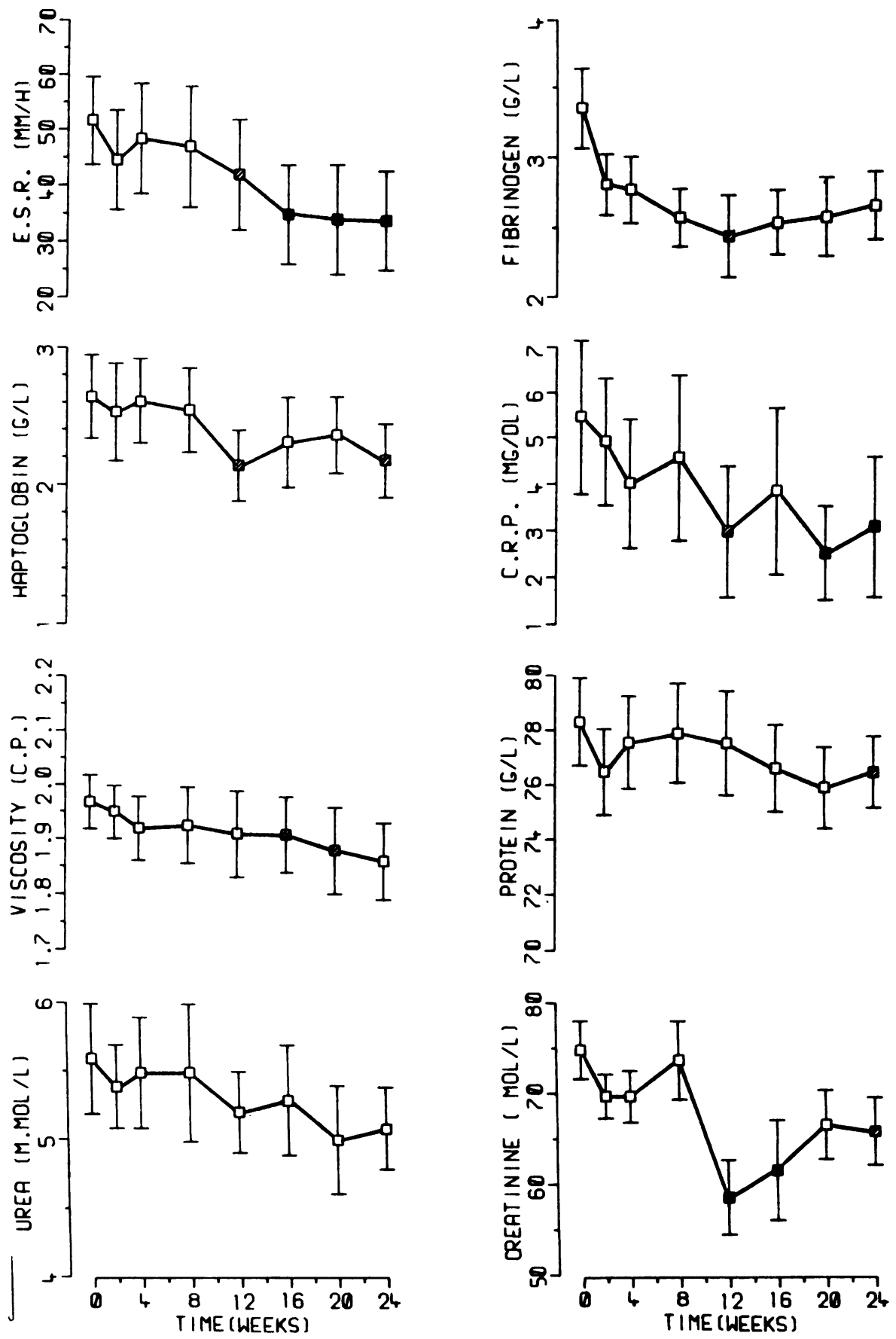

Fig. 2

Fig. 2 Laboratory data (mean $\pm S E$ ) for 15 RA patients treated for 6 months with D-penicillamine. Changes in individual parameters reaching statistical significance (Friedman rank test) when compared with data at week 0 are indicated by hatched $(P<0.05)$ and closed $(P<0.01)$ data points 

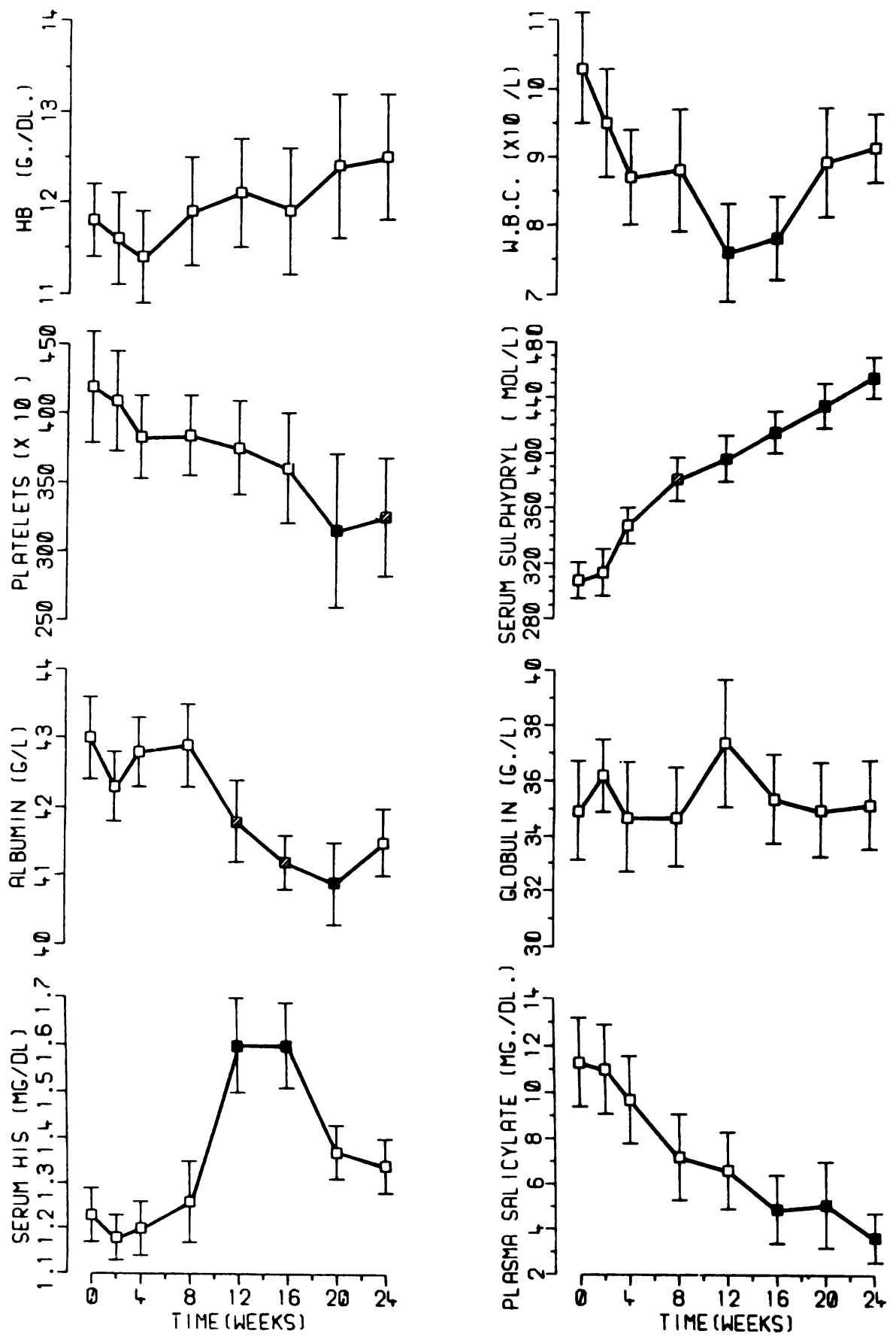

Fig. 2 

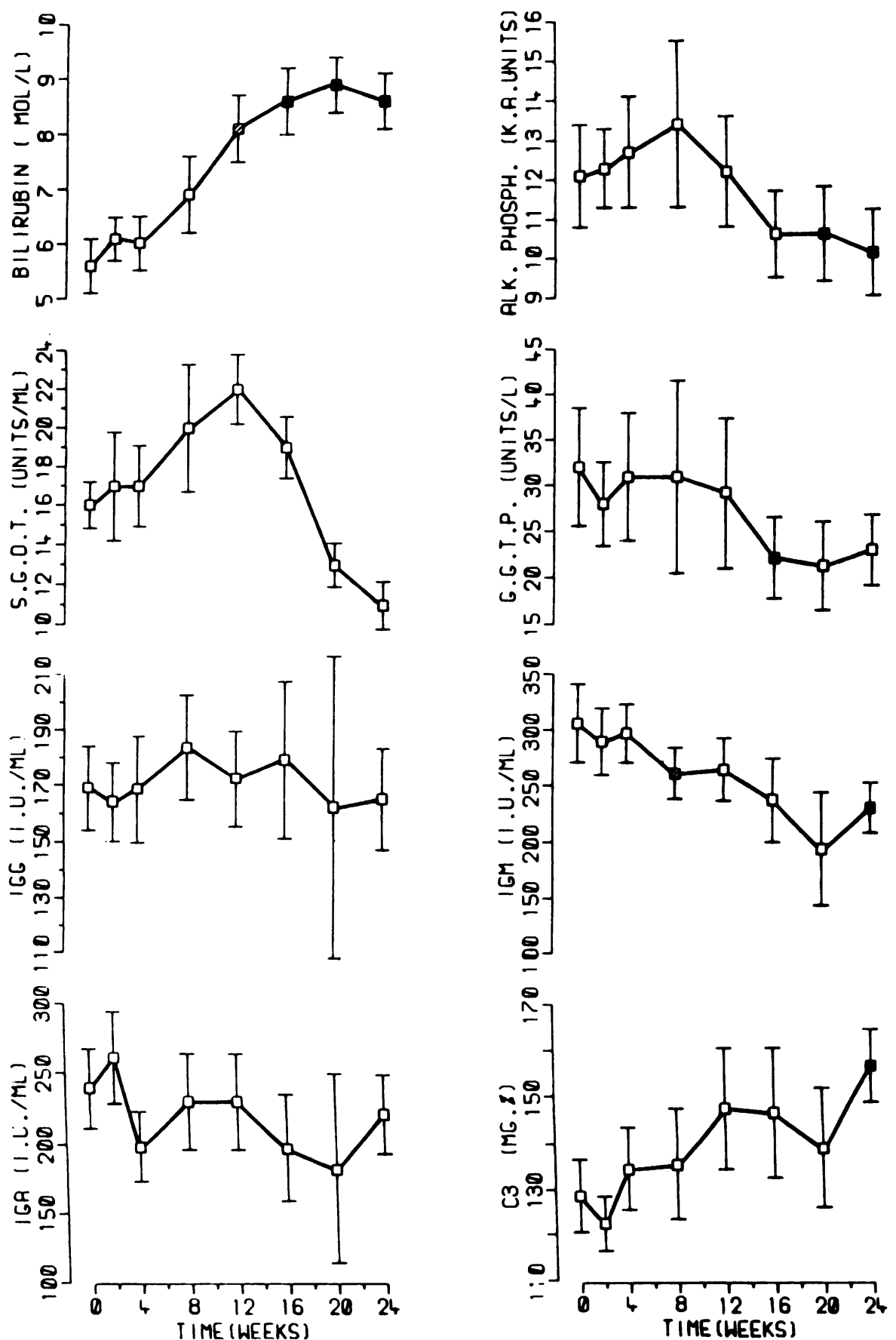

Fig. 2 


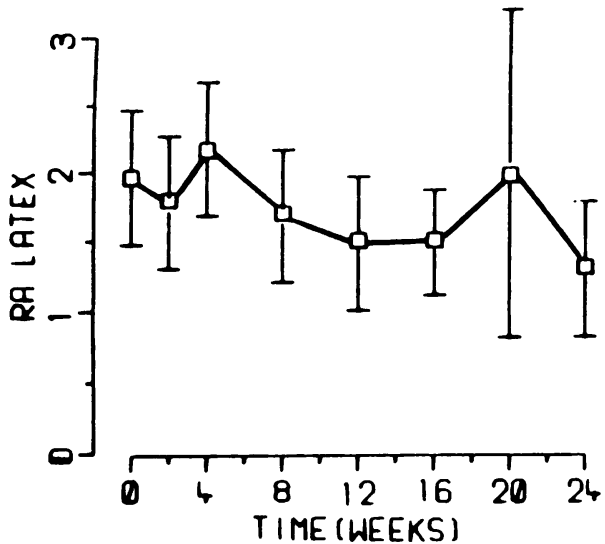

Fig. 2

changes in an individual of initially comparable disease activity but who responded well (Fig. 3a).

Correlation coefficients derived from individual patient data describing the interrelationship of individual systemic and clinical variables are available on request. The most notable correlations (all

Table 3 Correlations of biochemical parameters with clinical parameters $(R)$ and articular index $(r)$

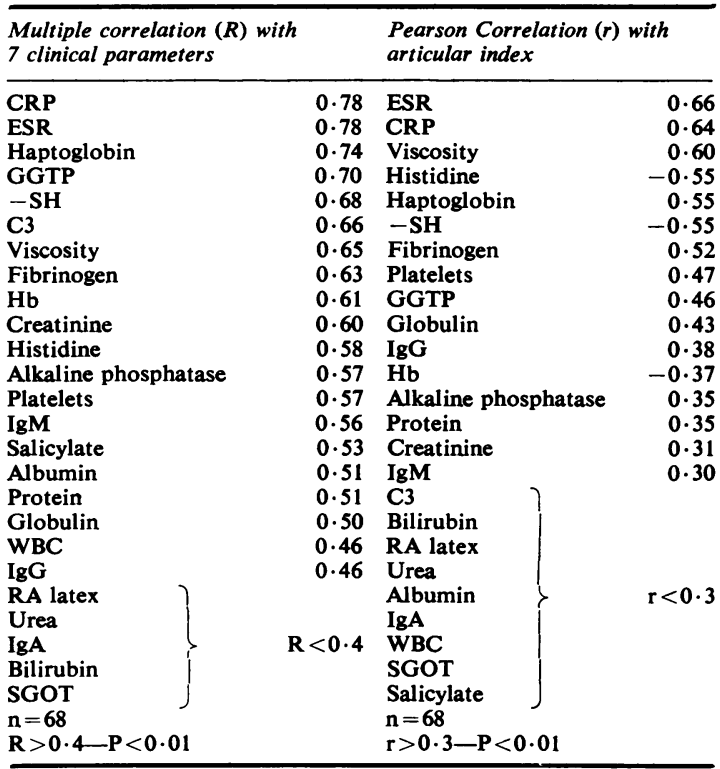

Table 2 A comparison of week 0 data for rheumatoid patients $(n=15)$ with $(a)$ data from normal volunteers matched for age and sex, and $(b)$ data from the literature

\begin{tabular}{|c|c|c|c|c|c|c|c|c|}
\hline \multirow[t]{3}{*}{ Parameter } & & \multirow{3}{*}{$\begin{array}{l}\text { Literature } \\
\text { range in } \\
\text { normals }(95 \%)\end{array}$} & \multicolumn{6}{|c|}{ Present study } \\
\hline & & & \multicolumn{2}{|l|}{ Week $O$} & \multicolumn{2}{|c|}{ Matched normals } & \multirow{2}{*}{$\begin{array}{l}P \text { level }< \\
\text { (week } O \text { vs. } \\
\text { matched } \\
\text { normals) }\end{array}$} & \multirow{2}{*}{$\begin{array}{l}\text { Week } O^{*} \\
\text { vs. matched } \\
\text { normals }\end{array}$} \\
\hline & & & Mean & $\pm S E$ & Mean & $\pm S E$ & & \\
\hline ESR & $\mathbf{m m} \cdot \mathbf{h}^{-1}$ & $\begin{array}{l}\text { Male } \\
10-25 \\
\text { Female }\end{array}$ & 52 & $8 \cdot 3$ & 5 & 0.9 & 0.001 & $\uparrow$ \\
\hline Fibrinogen & g. $1^{-1}$ & $2 \cdot 0-4 \cdot 0$ & 3.4 & $0 \cdot 3$ & $2 \cdot 13$ & $0 \cdot 1$ & 0.01 & $\uparrow$ \\
\hline Haptoglobin & g. $1^{-1}$ & $0 \cdot 3-2 \cdot 0$ & $2 \cdot 7$ & $0 \cdot 3$ & $1 \cdot 60$ & 0.09 & 0.01 & $\uparrow$ \\
\hline CRP & $\mathrm{mg} .100 \mathrm{ml}^{-1}$ & 0.0 & $5 \cdot 5$ & $1 \cdot 7$ & 0.0 & 0.0 & 0.01 & $\uparrow$ \\
\hline Plasma viscosity & c.p. & $1 \cdot 50-1 \cdot 72$ & 1.97 & 0.05 & 1.66 & 0.02 & 0.01 & $\uparrow$ \\
\hline Protein & g. $1^{-1}$ & $65-80$ & $78 \cdot 3$ & $1 \cdot 6$ & $73 \cdot 5$ & 0.6 & 0.01 & $\uparrow$ \\
\hline Albumin & g. $1^{-1}$ & $37-49$ & $43 \cdot 0$ & 0.6 & $44 \cdot 3$ & 0.8 & NS & - \\
\hline Globulin & g. $1^{-1}$ & $24-37$ & $34 \cdot 9$ & $1 \cdot 8$ & $29 \cdot 2$ & 0.7 & ID & ID \\
\hline GGTP & Units $1^{-1}$ & $\begin{array}{c}6-28 \\
\text { Male } \\
\text { 4-18 } \\
\text { Female }\end{array}$ & $32 \cdot 0$ & $6 \cdot 5$ & $20 \cdot 0$ & $3 \cdot 3$ & 0.05 & $\uparrow$ \\
\hline SGOT & Units $1^{-1}$ & $8-22$ & $16 \cdot 0$ & $1 \cdot 2$ & $19 \cdot 0$ & $1 \cdot 5$ & NS & - \\
\hline Alkaline phosphatase & K-A units & 4-13 & $12 \cdot 1$ & $1 \cdot 3$ & $7 \cdot 3$ & 0.7 & 0.01 & $\uparrow$ \\
\hline WBC & $\times 10^{9} .1^{-1}$ & $2 \cdot 8-11 \cdot 2$ & $10 \cdot 3$ & $0 \cdot 8$ & 6.9 & 0.4 & 0.01 & $\uparrow$ \\
\hline Haemoglobin & $\mathrm{g} .100 \mathrm{ml}^{-1}$ & $13 \cdot 4-17 \cdot 3$ & $11 \cdot 8$ & 0.4 & $13 \cdot 9$ & 0.4 & 0.01 & $\downarrow$ \\
\hline Creatinine & $\mu \mathrm{mol} .1^{-1}$ & $40-150$ & 75 & $3 \cdot 2$ & 91 & $4 \cdot 3$ & 0.01 & $\downarrow$ \\
\hline Urea & mmol.1-1 & $2 \cdot 5-7 \cdot 1$ & 5.6 & $0 . \overline{4}$ & $5 \cdot 0$ & 0.3 & NS & $\stackrel{v}{-}$ \\
\hline Platelets & $\times 10^{9} .1^{-1}$ & $160-600$ & 419 & 40 & 244 & $12 \cdot 4$ & 0.01 & $\uparrow$ \\
\hline Bilirubin & $\mu \mathrm{mol} .1^{-1}$ & 3-15 & $5 \cdot 6$ & 0.5 & $10 \cdot 0$ & $1 \cdot 0$ & 0.01 & $\downarrow$ \\
\hline Serum sulphydryl & $\mu \mathrm{mol} .1^{-1}$ & $400-600$ & 308 & 13 & 448 & $10 \cdot 5$ & 0.01 & $\downarrow$ \\
\hline Serum histidine & $\mathrm{mg} .100 \mathrm{ml}^{-1}$ & $1 \cdot 5-1 \cdot 8$ & $1 \cdot 23$ & 0.06 & $1 \cdot 52$ & 0.05 & 0.01 & $\downarrow$ \\
\hline Plasma salicylate & $\mathrm{mg.} 100 \mathrm{ml}^{-1}$ & 0.0 & $11 \cdot 3$ & 1.9 & 0.0 & 0.0 & 0.01 & $\uparrow$ \\
\hline IgG & IU. $\mathrm{ml}^{-1}$ & $128-199$ & 169 & 15 & 128 & $6 \cdot 6$ & 0.05 & $\uparrow$ \\
\hline IgM & IU. $\mathrm{ml}^{-1}$ & $60-129$ & 306 & 35 & 194 & 46 & 0.05 & $\uparrow$ \\
\hline IgA & IU. $\mathrm{ml}^{-1}$ & $97-181$ & 240 & 28 & 118 & 13 & 0.01 & $\uparrow$ \\
\hline $\mathrm{C}^{3}$ & $\mathrm{mg} \%$ & $80-140$ & 129 & 8 & 141 & 13 & NS & - \\
\hline RA latex & & 0.0 & $2 \cdot 0^{* *}$ & 0.5 & 0.0 & 0.0 & 0.01 & $\uparrow$ \\
\hline
\end{tabular}

*Week $O$ data increased $(\uparrow)$ or decreased $(\downarrow)$ compared with matched normals.

** Equivalent to a mean of $++. \mathrm{NS}=$ not significant. ID = insufficient data at week $O$. 


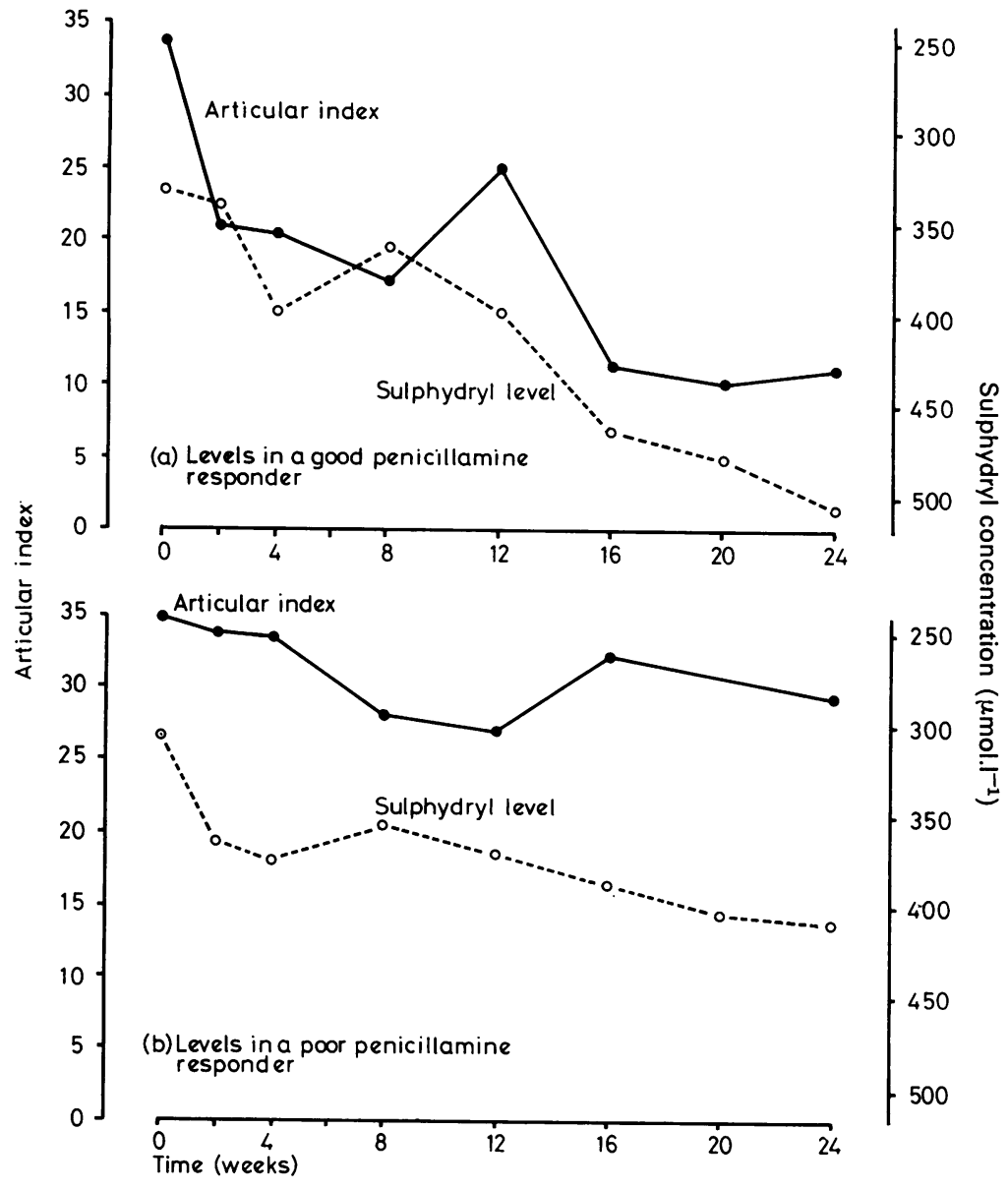

Fig. 3 (a) Articular index and total serum sulphydryl levels in a good penicillamine responder (b) articular index and total serum sulphydryl levels in a poor penicillamine responder NB: Total serum sylphydryl axis is inverted for clarity

with $\mathrm{P}<0.001$ ), however, were ESR with CRP $(\mathrm{r}=0 \cdot 82)$, with viscosity $(0 \cdot 81)$, with fibrinogen $(0 \cdot 75)$, and with haptoglobin $(0 \cdot 73)$. Viscosity correlated with globulin $(0 \cdot 86)$, with protein $(0 \cdot 91)$, with fibrinogen $(0 \cdot 80)$, and with IgG $(0 \cdot 76)$; CRP correlated with haptoglobin $(0 \cdot 82)$ and with fibrinogen $(0.71)$; and alkaline phosphatase correlated with GGTP $(0 \cdot 86)$.

Laboratory parameters are ranked (Table 3) according to the degree of correlation with 'disease activity', obtained from a multiple regression of each parameter in terms of articular index, grip strength, joint circumference, functional grade, pain score, summated change score, and early morning stiffness. The most relevant indices of disease activity were CRP and ESR. On the assumption that articular index is the most relevant clinical parameter, ${ }^{6}$ it was correlated with each laboratory parameter in turn, and again CRP and ESR were found to correlate the most.

\section{Discussion}

The finding in RA patients of systemic variables displaced from normal has been previously reported; the present work confirms these findings. For example, low haemoglobin, ${ }^{11}$ creatinine and bilirubin, ${ }^{12}$ sulphydryl, ${ }^{13}$ and histidine levels ${ }^{14}$ have been reported, while high levels have been recorded in the acute phase proteins and ESR, ${ }^{3}$ plasma viscosity, ${ }^{15}$ platelet count, ${ }^{16}$ alkaline phosphatase, ${ }^{17}$ gamma glutamyl transpeptidase, ${ }^{18}$ white cell count and globulin, ${ }^{12}$ immunoglobulins and RA latex. ${ }^{1920}$ Previous reports of low albumin levels ${ }^{21}$ were not confirmed in the present study. The use of a matched normal group for comparative purposes was necessary in view of previous reports of the dependence of many systemic variables on age and sex. ${ }^{112} 1422$

The observed delayed response to penicillamine (weeks 12-16) is well documented ${ }^{23-25}$ The present results support the view that penicillamine has a 
'specific action' in that it seems to change the course of the disease. ${ }^{326} 27$ This change was observed in terms of a return towards normal levels in the acute phase proteins, i.e., fibrinogen, CRP, haptoglobin, and ESR (Fig. 2). However, significant changes either towards normal or within the normal range were also recorded in plasma viscosity, alkaline phosphatase, gamma glutamyl transpeptidase, bilirubin, total protein, creatinine, white cell and platelet count, serum sulphydryl, serum histidine, plasma salicylate, $\operatorname{IgM}$, and $\mathrm{C} 3$.

Not all these changes necessarily reflect improvement in disease activity. The mean white cell count dropped towards the lower end of the normal range between weeks 8 and 16; this may well have been a drug induced side effect. Similarly, the drop in platelet count may be a drug induced side effect, particularly as some individual counts were reduced towards the lower end of the accepted normal range. However, platelet counts at week 0 , although within the literature quoted normal range, were high compared with the matched controls (Table 2). Thrombocytosis has been previously reported in $\mathrm{RA},{ }^{16}$ and thus any reduction in count may reflect disease improvement rather than side effect.

The increase in serum sulphydryl level during penicillamine therapy may be a result of one or more processes. Firstly, a direct action of penicillamine to increase protein sulphydryl levels may be responsible. This has been reported in vitro and suggests a possible mode of action of the drug. ${ }^{28}$ Secondly, serum sulphydryl levels may increase as an indirect response to the therapeutic action of the drug. Studies in progress, estimating sulphydryl levels following therapy with 'non-thiol' drugs may clarify this situation.

The increase in serum histidine may also reflect either a direct action of the drug or nonspecific disease improvement. This has been recently discussed. ${ }^{29}$

The reduction in salicylate level (Fig. 2) is not surprising in view of the patients' instructions to reduce the aspirin dose as they improved. Evidence of aspirin's failure to affect many other parameters 3273031 suggests that systemic changes are penicillamine-induced rather than a consequence of nonspecific anti-inflammatory drug treatment.

Haemoglobin levels provide one example in the present study of findings which differ from those hitherto reported. Although an upward trend was observed (Fig. 2), the patients' anaemia failed to respond significantly to penicillamine treatment whereas previous reports have indicated significant improvement during treatment. ${ }^{25}{ }^{32}$ The concurrent aspirin therapy may be responsible for this lack of response. However, an enteric coated preparation was used, minimising gastric bleeding, and the dose was reduced over the 24-week period. A second variation from earlier literature ${ }^{33-35}$ would appear to be IgG and IgA levels, which were not significantly reduced by penicillamine therapy.

The study has demonstrated strong correlations between individual variables, both clinical and systemic. Many of these were expected. For example, the correlation between ESR and the acute phase proteins has been previously demonstrated by Crockson and Crockson ${ }^{36}$ and by Haataja. ${ }^{1}$ Plasma viscosity has been correlated with globulin, ${ }^{37}$ with ESR, and with acute phase proteins. ${ }^{36}$ The observed relationship between alkaline phosphatase and GGTP would be consistent with liver involvement in RA. ${ }^{17} 38$

The finding that ESR and CRP are the most useful indices of disease activity in RA confirms earlier reports. ${ }^{39} 40$ However, unlike earlier work the present information is based on data obtained from individuals during successive clinic visits, i.e., ESR and CRP are also the most useful indices of change in clinical status during treatment with penicillamine and aspirin supplement. Furthermore, clinical status has been represented in terms of a wide range of clinical measures.

The use of immunoglobulins as indices of clinical activity is much disputed. Claman and Merrill ${ }^{41}$ and Veys and Claessens ${ }^{19}$ have shown some association with activity, whereas Marcolongo et al..$^{42}$ and Farr et al. ${ }^{40}$ showed none. Our results (Table 3) indicate that $\operatorname{IgG}$ and $\operatorname{IgM}$ levels correlate with disease activity but they were not the most useful indices.

Our results have shown unequivocally a definite clinical and laboratory improvement with penicillamine. Moreover, they also suggest that the best discriminant laboratory indices are ESR and CRP. Some of these laboratory changes such as those in sulphydryl concentration may be fundamental to the process of rheumatoid arthritis rather than nonspecific accompaniments of the disease state. Our further studies, using alternative antirheumatoid drugs, should serve to distinguish those laboratory measurements which are specific to the disease process and those changes that are drug induced. In this way we may yet gain more insight into the basic nature of the pathological process in rheumatoid arthritis.

The Clinical Pharmacology Unit gratefully acknowledges the financial support of Roche Products Limited.

The authors wish to thank Mrs P. A. Leatham and Mrs V. M. Rhind for the clinical assessments, Dr W. W. Downie and Dr H. A. Bird for helpful discussion, and Mrs D. K. Smith for secretarial assistance. 


\section{References}

1 Haataja M. (1975). Evaluation of the activity of rheumatoid arthritis. Scand J Rheumatol 1975; 4: Suppl. 7, 5-54.

2 Kendall M J. Biochemical studies in the assessment of rheumatic diseases. Clin Rheum Dis 1976; 2: 253-271.

3 McConkey B, Crockson R A, Crockson A P, Wilkinson A R. The effects of some anti-inflammatory drugs on the acute-phase proteins in rheumatoid arthritis. $Q \mathrm{~J}$ Med 1973; 42: 785-791.

4 Maddock J, Rees P, Holly F, Aylward M. The influence of alclofenac treatment on acute-phase proteins, plasma tryptophan, and erythrocyte sedimentation rate in patients with rheumatoid arthritis. Curr Med Res Opin 1975; 3: 286-297.

5 Evans P H. Serum sulphydryl levels in rheumatoid patients treated with alclofenac. Curr Med Res Opin 1975; 3: 268-273.

- Ritchie D M, Boyle J A, McInnes J M, et al. Clinical studies with an articular index for the assessment of joint tenderness in patients with rheumatoid arthritis. $Q J$ Med 1968; 37: 393-406.

7 Siegel S. Non-parametric statistics for the Behavioural Sciences. McGraw-Hill, 1956; 75.

8 Wilcoxon F, Wilcox R A. Some Rapid Approximate Statistical Procedures. Lederle Laboratories, 1964 ; 11.

9 Sokal R R, Rohlf F J. Biometry: Freeman, 1969; 494.

10 Cohen J, Cohen P. Applied Multiple Regression. Lawrence Erlbaum Ass. 1975; 91.

11 Grennan D M, Anderson J A, Kennedy A C, Mitchell W, Dick C W, Buchanan W W. Relationship between haemoglobin and the other clinical and laboratory parameters in rheumatoid arthritis. Curr Med Res Opin 1975; 3: 104-108.

12 Wilding P, Kendall M J, Holder R, Grimes J A, Farr M. The influence of drugs and disease activity on biochemical and haematological data in rheumatoid arthritis. Clin Chim Acta 1975; 64: 185-194.

13 Lorber A, Pearson C M, Meredith W L, Gantz-Mandell L E. Serum sulphydryl determination and significance in connective tissue disease. Ann Intern Med 1964; 61: 423-434.

14 Gerber D A, Gerber M G. Specificity of a low free serum histidine concentration for rheumatoid arthritis. J Chron Dis 1977; 30: 115-127.

15 Blades A N, Coyer A B, Flavell H C G. Plasma viscosity with particular reference to its estimation in cases of rheumatoid-type arthritis. Ann Phys Med 1966; 8: 214219.

16 Ehrenfeld M, Penchas S, Eliakim M. Thrombocytosis in rheumatoid arthritis. Ann Rheum Dis 1977; 36: 579581.

17 Kendall M J, Cockel R, Becker J, Hawkins C F. Raised serum alkaline phosphatase in rheumatoid disease. Ann Rheum Dis 1970; 29: 537-540

18 Lowe J R, Pickup M E, Dixon J S, et al. Gamma glutamyl transpeptidase levels in arthritis: a correlation with clinical and laboratory indices of disease activity. Ann Rheum Dis 1978; 37: 428-431.

19 Veys E M, Claessens H E. Serum levels of IgG, IgM and IgA in rheumatoid arthritis. Ann Rheum Dis 1968; 27: 431.

20 Swanell A J, Watkins J. The influence of drug therapy on serum immunoglobulin profiles in rheumatoid arthritis. Proc R Soc Med 1977; 70: 140-141.

21 Cockel R, Kendall M J, Becker J F, Hawkins C F. Serum biochemical values in rheumatoid disease. Ann Rheum Dis 1971; 30: 166-170.
22 Böttiger L E, Svedberg C A. Normal erythrocyte sedimentation rate and age. $B r$ Med $J$ 1967; 2 : 85-87.

23 Gibson T, Huskisson E C, Wojtuleuski J A. et al. Evidence that D-penicillamine alters the course of RA. Rheumatol Rehabil 1976; 15: 211-215.

24 Berry H, Fernandes L, Ford-Hutchinson A W, Evans S J W, Hamilton E B D. Alclofenac and D-penicillaminecomparative trial in RA. Ann Rheum Dis 1978; 37: 93-97.

25 Dixon A St J, Davies J, Dormandy T L et al. Synthetic है D(-)Penicillamine in RA. Ann Rheum Dis 1975; 34: 416-421.

26 McConkey B, Crockson R A, Crockson A P. The assessment of rheumatoid arthritis. $Q J$ Med 1972; 41: 115125.

27 Aylward M, Maddock J, Wheeldon R, Parker R J. A study of the influence of various anti-rheumatic drug regimens on serum acute-phase proteins, plasma tryp- $\subseteq$ tophan and erythrocyte sedimentation rate in rheumatoid arthritis. Rheumatol Rehabil 1975; 14: 101-114.

28 Lorber A, Chang C C, Masuoka D, Meacham I. Effect of thiols in biological systems on protein sulphydryl content. Biochem Pharmacol 1970; 19: 1551-1560.

29 Pickup M E, Dixon J S, Lowe J R, Wright V. Serum histidine in rheumatoid arthritis: changes induced by anti-rheumatic drug therapy. $J$ Rheumatol 1980 ; in press.

30 Aylward M, Parker R, Holly F, Maddock J, Davies D B S. Long-term study of indomethacin and alclofenac in treatment of rheumatoid arthritis. $B r$ Med $J$ 1975; 2: 79.

31 Gerber D A, Cohen N, Giustra R. The ability of nonsteroid anti-inflammatory compounds to accelerate a disulphide interchange reaction of serum sulphydryl groups and 5,5'-Dithiobis (2-nitrobenzoate). Biochem Pharmacol 1967; 16: 115-123.

32 Mäkisara P, Nisillä M, Kajander A, et al. Comparison $\unrhd$ of penicillamine and Gold Treatment in Early Rheumatoid Arthritis. Scand J Rheumatol 1978; 7: 166-170.

33 Bluestone R, Goldberg L S. Effect of D-penicillamine on serum immunoglobulins and rheumatoid factor. $A n n$ Rheum Dis 1973; 32: 50-52.

34 Huskisson E C, Berry H. Some immunological changes in rheumatoid arthritis among patients receiving peni- $\bar{\varrho}$ cillamine and gold. Postgrad Med J 1974; August Suppl. 59-61.

35 Stanworth D R, Johns P, Williamson N, Shadforth M, Felix-Davies D, Thompson $R$. Drug-induced IgA deficiency in rheumatoid arthritis. Lancet 1977; 1: 1001-1002.

${ }^{36}$ Crockson $\mathrm{R}$ A, Crockson A P. Relationship of the erythrocyte sedimentation rate to viscosity and plasma proteins in rheumatoid arthritis. Ann Rheum Dis 1974; 33: 53-56.

37 Shearn M A, Epstein W V, Engleman E P, Taylor W F. Relationship of serum proteins and rheumatoid factor to serum viscosity in rheumatic diseases. J Lab Clin Med N $1963 ; 61$ : 677 .

88 Sullivan S, Hamilton E B D, Williams R. Rheumatoid arthritis and liver involvement. $J \boldsymbol{R}$ Coll Physicians Lond 1978; 12: 416-422.

39 Haataja M, Kalliomaki J L. Laboratory scale for evaluating the activity of RA. Rheumatol Rehabil 1978; 17: 83-85.

40 Farr M, Kendall M J, Young D W, Meynell M J, Hawkins $\overrightarrow{\mathbb{D}}$ C F. Assessment of rheumatoid activity based on clinical $\Omega$ features and blood and synovial fluid analysis. Ann Rheum Dis 1976; 35: 163-167.

11 Claman H N, Merrill D A. Serum immunoglobulins in rheumatoid arthritis. J Lab Clin Med 1966; 67: 850. 
42 Marcolongo R, Carcassi A, Frullini F, Bianco G, Bravi A. Levels of serum immunoglobulins in patients with rheumatoid arthritis. Ann Rheum Dis 1967; 26: 412.

43 Mancini G, Carbonara A D, Heremans J F. Immunochemical quantitation of antigens by single radial immunodiffusion. Immunochemistry 1965; 2: 235-254.

44 Ratcliff A P, Hardwicke J. A method for the measurement of serum haptoglobin. J Clin Path 1964; 17: 656679.
45 Jacobs W L W. A colourimetric assay for $\gamma$-glutamyltranspeptidase. Clin Chim Acta 1971; 31: 175-179.

46 Harkness J. The viscosity of human blood plasma: its measurement in health and disease. Biorheology 1971; 8: 171-193.

47 Gerber D A. Determination of histidine in serum with O-Phthaldialdehyde. Anal Biochem 1970; 34: 500-504.

48 Trinder P. Rapid determination of salicylate in biological fluids. Biochem J 1954; 57: 301-303. 